\title{
Políticas de gênero para a Defesa: os casos de Argentina e Brasil
}

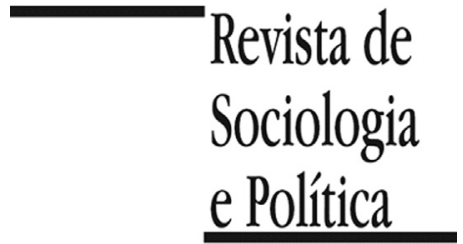

DOI 10.1590/1678-987317266501

\section{Natália Diniz Schwether iD e Graciela de Conti PagliarifiD}

\begin{abstract}
RESUMO Introdução: O artigo elenca as políticas de gênero para defesa, adotadas pelos governos da Argentina e do Brasil, de 2005 a 2015. A relevância do caso argentino decorre de o país ter se demonstrado bastante ativo, por meio de práticas de seu Ministério da Defesa. Por outro lado, no Brasil, ressalta-se a criação da Comissão de Gênero, no âmbito do Ministério da Defesa, que visa a efetivação dos direitos das mulheres e da igualdade de gênero. Métodos: Para tanto, estabelece-se um estudo qualitativo, processual e histórico de fontes primárias advindas de publicações anuais, relatórios e atas de reuniões, em ambos os países. Resultados: A partir da análise dos dois casos depreende-se que, mesmo diante de um cenário no qual a incorporação efetiva das mulheres ainda não foi concluída, a instituição de um Ministério da Defesa forte e impositivo, capaz de controlar as políticas propostas, atrelado a uma condução que estabeleça a equidade como um de seus pressupostos, foram os requisitos que possibilitaram à Argentina tornar-se uma expoente regional na temática de gênero. Discussão: Embora verifique-se a atualidade do debate a respeito do gênero nas forças armadas, as contribuições científicas ao campo são exíguas. Desta maneira, os resultados apresentados são uma forma de atualizar os dados empíricos sobre a questão e fornecer insumos para ampliação da discussão sobre gênero nas Forças Armadas na América Latina.
\end{abstract}

PALAVRAS-CHAVE: forças armadas; Ministério da Defesa; gênero; Brasil; Argentina.

Recebido em 16 de Novembro de 2016. Aceito em 19 de Abril de 2017.

\section{Introdução ${ }^{1}$}

\footnotetext{
1 Esse artigo desenvolve discussões feitas na dissertação de mestrado "Agora é que são elas: desvendando o processo de incorporação das mulheres nas Forças Armadas de Brasil e Argentina", defendida por Natália Diniz Schwether em fevereiro de 2016, no Programa de Pós-Graduação em Relações Internacionais da UFSC. Os dados ora apresentados foram atualizados até essa data. Agradecemos aos comentários e sugestões dos pareceristas anônimos da Revista de Sociologia e Política.
}

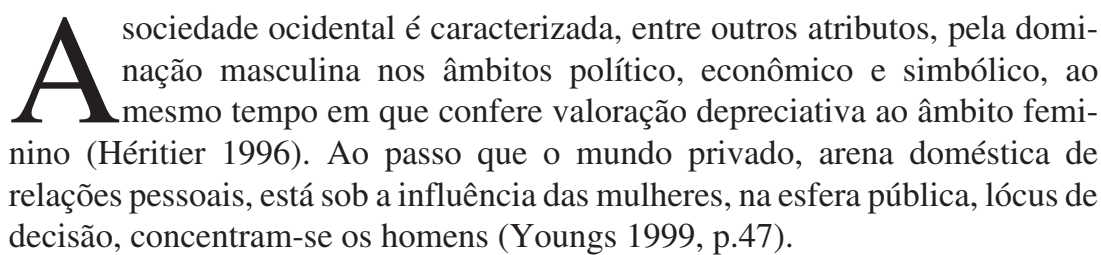

Sendo assim, "cada sexo tem sua função, seus papéis, suas tarefas, seus espaços, seu lugar, quase predeterminados, até seus detalhes" (Perrot 1988, p.178 apud Scott 1989). Alia-se a essa concepção a importância do contexto cultural. Sob o prisma de uma masculinidade hegemônica, as normas e as instituições almejam manter a autoridade dos homens em um ambiente cultural e midiático que naturaliza a opressão feminina.

Em uma sociedade na qual prevalecem os estereótipos socialmente construídos, há maior valorização das atividades desempenhadas por homens, bem como determinados postos de trabalho são considerados inapropriados para as mulheres. Logo, o critério do sexo de quem executa a atividade é preponderante, exigindo-se da mulher mais atributos no desemprenho de uma mesma função.

No que tange ao objeto deste artigo, as forças armadas são consideradas uma instituição patriarcal, na qual reifica-se a posição dos homens como dominantes (Chambouleyron \& Resende 2006). O caráter assimilador da organização faz com que as mulheres percam sua identidade de gênero. Estabelece-se, dessa maneira, uma relação de subordinação entre homens e mulheres militares (Bobea 2008). São impostas barreiras sutis e transparentes, mas suficiente- 
${ }^{2}$ Conceito cunhado como teto de vidro, introduzido na década de 1980 nos Estados Unidos, que enfatiza as desigualdades de gênero utilizadas como forma de opressão, as quais resultam em uma sub-representação feminina nos cargos de comando das organizações (Stell 1997; Vaz 2013).

\footnotetext{
${ }^{3}$ Entre os movimentos de maior destaque estão o sufragista e, no campo da saúde, a regulamentação dos anticoncepcionais, os quais garantiriam o controle da fertilidade e a possibilidade de realizarem um planejamento familiar (Friedman 2003).
}

mente fortes que impossibilitam a ascensão das mulheres aos níveis mais altos da hierarquia organizacional, exclusivamente em função de seu gênero ${ }^{2}$.

Em situações de conflito, por exemplo, o gênero masculino constitui, tendencialmente, o sujeito ativo, na forma de guerreiro, ao passo que o gênero feminino é o ente passivo, confundido com a presa. Às mulheres poupa-se o papel de combatente, mas não o de vítimas, na forma de estupros, utilizados para desmoralizar, punir e humilhar o inimigo (Battistelli 1999). Portanto, mesmo que as mulheres ao longo da história estivessem presentes nas forças armadas, em sua maioria, estavam restritas ao ambiente doméstico, no qual exerciam papel de apoio na composição da família militar, sendo a exclusão das demais atividades justificada por aspectos de ordem física.

No meio castrense, o preconceito evidencia-se não apenas pelas restrições impostas, mas, principalmente, pelo tratamento e julgamento conferido às mulheres (Mathias 2005). Inicialmente, elas são confrontadas por expectativas sociais do que é ser uma mulher. Uma mulher não desejaria carregar armas, dormir em cabanas ou ter a sua higiene pessoal prejudicada, a menos que sua finalidade fosse a de casar-se, ter experiências sexuais ou serem homossexuais (Herbert 1998). No entanto, ao contrário desse pensamento machista, de acordo com Carreiras (2013), são justamente características como a disciplina e a aventura que atraem as mulheres para a instituição.

Por essa razão, a partir da década de 1980, embora com as recorrentes dúvidas sobre as reais intenções femininas, as mudanças políticas mundiais, a democratização das sociedades e a expansão dos direitos de igualdade entre gêneros - acrescidos da ressignificação dos papéis das mulheres na sociedade, decorrentes das transformações econômicas e sociais, bem como dos movimentos feministas - impulsionaram a incorporação de um contingente feminino na estrutura militar (D'Araújo 2003).

Destacam-se os esforços realizados pelas mulheres para que suas demandas transcendessem as fronteiras nacionais e se conjugassem em uma voz comum ${ }^{3}$. Essas articulações transnacionais, ao longo dos anos, conquistaram espaço proeminente também nas conferências mundiais das Organizações das Nações Unidas (ONU), a qual instituiu, na década de 1980, a Década da Mulher (1975-1985). A partir de então, foram realizadas conferências em diferentes países para o fortalecimento da questão de gênero. $\mathrm{O}$ objetivo central era o empoderamento feminino. Nesse sentido, "o maior sucesso do movimento de direitos das mulheres foi 'gendrificar a agenda"' (Friedman 2003, p.313).

As estratégias de ação focaram em estabelecer contato com os representantes governamentais para a formulação de políticas públicas que atendessem às demandas das mulheres. A inserção de novos temas na agenda colocou um desafio aos paradigmas estabelecidos mundialmente, conquanto as mulheres conferiram à sociedade uma oportunidade de reflexão. Neste cenário as forças armadas não poderiam ficar alheias à mudança da mentalidade social (Martínez 2009).

Concomitantemente, muitos dos países sul-americanos vivenciavam o mesmo contexto político, compreendido pelo fim das ditaduras e pelo processo de democratização. Diante desse contexto, a forte interferência castrense na política foi substituída por um controle civil, ainda que limitado, sobre as forças armadas, o que garantiu o respeito às regras do novo governo democrático e a vocalização de novas demandas. De acordo com Baquim (2007, p.167), “o emprego das mulheres foi crescendo aos poucos, tanto dentro dos próprios países que já as incluíam, quanto nas fileiras de países que tradicionalmente condenavam tal opção, como é o caso de muitos países latino-americanos". 
No Brasil, em 1979, no decurso de sua transição democrática, o então senador Orestes Quércia propôs um projeto para o ingresso voluntário das mulheres nas escolas militares de nível superior, o que, em sua opinião, estava em consonância com o processo mundial de profissionalização das forças armadas e com a luta dos movimentos feministas. No entanto, recebeu parecer negativo, embasado na estrutura corporal feminina e na função social das mulheres, ambas incompatíveis com as exigências das Forças Armadas (Almeida 2008).

Por outro lado, a carência de mão de obra garantiu mais adeptos à proposta, afinal as mulheres seriam alocadas em serviços auxiliares, compatíveis com a constituição do biotipo feminino. A Lei 6.807, de 07/07/1980, instituiu o Corpo Auxiliar Feminino da Reserva da Marinha (CAFRM), porém com claras limitações. As mulheres deveriam realizar as atividades apenas em terra, de acordo com as necessidades da Marinha, pautadas por normas de conduta ético-militar e de apresentação pessoal, sendo que aquilo que destoasse da norma deveria ser autorizado pelos superiores. A jornada extenuante, a dificuldade de atrelá-la com as demandas domésticas e da maternidade, e as limitadas chances de avanço na carreira resultaram em um alto índice de desistências e na perda de muitas profissionais qualificadas (Santos 2014).

Na Argentina, observa-se a inserção das mulheres nos corpos profissionais das forças armadas em meio ao conflito das Malvinas, o que gerou um caráter de urgência à ação e, por essa razão, as mulheres se depararam com uma instituição ainda despreparada estruturalmente para recebê-las. Os abrigos para as tropas não detinham infraestrutura necessária para o compartilhamento com mulheres, a exemplo dos banheiros. Da mesma forma que faltavam diretrizes para reger as mais diversas situações, entre elas os uniformes, a maternidade, o combate (Granizo 2008). Nos demais quadros, o fim do Serviço Militar Obrigatório, em 1994, teria sido uma mudança contundente no âmbito castrense, uma vez que, além da alternância de um sistema de conscrição obrigatória para o recrutamento voluntário, foi aceito o ingresso de mulheres. Com isso, o serviço militar deixou de representar um rito de passagem masculino e passou a representar uma oportunidade para os jovens de ambos os sexos. Eram recorrentes os casos em que a precariedade social motivava as apresentações para o alistamento. "Muitas eram meninas sem estudos e em estado de pobreza extrema, que buscavam escapar do trabalho como empregadas domésticas" (Badaró 2015, p.91).

Em paralelo ao avanço da democratização, foram introduzidas as primeiras políticas públicas com recorte de gênero. O processo foi liderado por grupos de mulheres e feministas que, inicialmente, possuíam uma agenda com pautas voltadas para a democratização e a obtenção de direitos. Entretanto, no decorrer dos anos, complexaram suas causas e, no final dos anos 1980, os temas permeavam a igualdade de status, a eliminação da discriminação sexual, a introdução de regulamentos contra assédio sexual e violência doméstica, bem como a inserção de cotas que garantissem a representatividade feminina (Farah 2004; Stromquist 1996). Reivindica-se a inclusão das mulheres como beneficiárias das políticas, mas, fundamentalmente, a sua participação na formulação, implementação e controle das políticas.

Frisa-se, portanto, que esta agenda política favorável à população feminina foi impulsionada pelos movimentos de mulheres no exercício dos direitos conquistados pela cidadania, em um contexto democrático. Contudo, como se vislumbra na prática, o desenvolvimento de políticas de gênero ou que incorporem tal perspectiva ainda é um processo em construção e bastante complexo, já que envolve questões enraizadas culturalmente. Afirmar que a política deve integrar a dimensão de gênero significa identificar os segmentos sociais que 
estão reforçando preconceitos, estereótipos, relações de poder e de subjugação (Soares 1994) e fazer com que esses incluam, explicitamente em seus objetivos, a equidade de gênero.

Esse é o caso do segmento militar, no qual as mulheres são comumente excluídas de certas especialidades, sendo que os postos centrais da instituição são dominados, em termos numéricos, por homens, em especial aquelas funções que garantem maior prestígio e possibilidades de ascensão na carreira. Da mesma forma, a cultura e a ideologia foram desenvolvidas a partir de definições tradicionais e concepções masculinas (Carreiras 2010). Nesse sentido, o âmbito da defesa, entendido como um bem público garantido à sociedade, foi eleito como lócus para aplicação das políticas.

A defesa é uma atividade típica do Estado, indelegável para o setor privado, uma vez que sua realização somente é possível com a intervenção da força estatal. Do ponto de vista político, ela deve constituir uma política de Estado e não uma política de governo, a fim de que seja conduzida acima de simples rivalidades, com participação ativa da sociedade. De acordo com Saint-Pierre:

\begin{abstract}
"O processo democrático demanda que a elaboração de políticas públicas contemple a participação efetiva da sociedade, ou, ao menos, do setor organizado desta. Nos casos em que a democracia está consolidada, participam do processo decisório no âmbito governamental membros do poder Executivo, parlamentares, acadêmicos, sindicatos, organizações não-governamentais, etc. Na perspectiva das democracias liberais ocidentais, para que uma democracia atenda minimamente às expectativas dos governados e cumpra, portanto, sua finalidade de representar de alguma forma as massas que se mobilizam no exercício da cidadania, devem ser estabelecidos mecanismos que combatam a centralização das decisões por um único setor, garantindo-se, assim, a pluralidade nas decisões na esfera pública" (Saint-Pierre 2014, p.1).
\end{abstract}

O exposto acima coaduna com o compromisso estabelecido na Carta Democrática Interamericana, a qual afirma que a segurança e a defesa são responsabilidade dos Estados e da sociedade e que a sua gestão democrática não é exclusiva das forças armadas (Saint-Pierre 2014 p.13). Tendo em vista que "ao superar o passado autoritário, uma parte articulada da sociedade rejeitou as Forças Armadas" (Oliveira 2006), atualmente a retomada de interesse desses setores é fundamental para que se obtenha maior legitimidade na construção das políticas. Embora as Forças Armadas não sejam mais independentes no processo de construção e aplicação da política de defesa, no Brasil, elas ainda mantêm um alto grau de autonomia. Logo, a presença de novos atores civis, públicos ou privados, colabora para diminuir a primazia militar (Rocha 2008), dado que relações civis-militares pouco solidificadas podem representar um entrave para a conquista de iniciativas concretas nas articulações políticas.

Mediante a apresentação desse panorama geral, depreende-se que, em ambos os contextos, a participação feminina, incrementada a partir da década de 1980, impeliu uma adequação das instituições em termos físicos e regulamentares, porém, embora tenham existido tentativas de reconfiguração na abordagem do tema, este ainda não recebeu o enfoque necessário e carece de constante atualização.

Dessa forma, o artigo trata, primeiramente, do caso argentino, para, a seguir, se deter sobre o caso brasileiro, de maneira a evidenciar as políticas que foram propostas por ambos os países na última década (2005-2015) relativas à condição das mulheres na organização militar. O método de análise qualitativo é utilizado com intuito de descrever os fenômenos políticos contidos no contexto social, mediante uma abordagem histórica, na qual busca-se identificar os eventos, processos e decisões-chave para consecução dos resultados. Para tanto, utilizam-se como fontes primárias publicações e documentos oficiais dos 
governos, em conjunto com atas e relatórios de reuniões obtidos através da Lei de Acesso à Informação brasileira.

\section{O cenário argentino}

${ }^{4}$ Dados divulgados pelo Ministério da Defesa argentino em 2014.
Na Argentina, as mulheres representam 14\% das Forças Armadas ${ }^{4}$. A presença feminina no meio militar foi responsável por alterar as dinâmicas internas. Acostumados com a presença exclusiva de militares homens, houve dificuldades de adaptação, principalmente, no que tange à forma de tratamento. Afinal, as mulheres foram autorizadas a ocupar postos sem que houvesse planejamento e políticas adequados para recepcioná-las. Diante de tal situação, o comportamento ficou a critério de opiniões individuais. Tal desorientação daria os primeiros passos para ser solucionada em 2005, com a ascensão da ministra de defesa Nilda Célia Garré (2005-2010).

Ao assumir o cargo de ministra, Nilda Garré acrescenta no processo de democratização da instituição militar a alteração dos padrões relacionais de gênero, pleiteando novos paradigmas para as forças (Barrancos 2015). Em sua administração, houve importantes evoluções normativas, embasadas por princípios dos direitos humanos, do direito do trabalho e da equidade de gênero. Mais detalhadamente, o seu plano de modernização do sistema de defesa era sustentado por dez grandes linhas, quais sejam: 1) estruturação orgânica, delegando ao Estado-Maior Conjunto o papel de assessor do Ministério e principal executor das decisões estratégicas, configurando-o como condutor operacional; 2) organização do planejamento estratégico, a partir do diagnóstico da situação atual, sua evolução e os critérios que devem orientar as ações futuras; 3) configuração de um sistema otimizado de execução logística, a partir de um estudo que identificou erros e fissuras nos processos e que propiciou a criação de uma agência formada por civis e militares para reverter o quadro; 4) articulação entre as áreas de investigação, desenvolvimento e produção; 5) consolidação da integração regional e cooperação internacional, a partir da constituição de forças de paz e treinamento conjunto (Cruz del Sur, ALCOPAZ), assistência humanitária e o estabelecimento de diálogos estatais (Conselho de Defesa Sul-Americano); 6) promoção da educação, pautada em valores democráticos, com a profissão militar devendo ser promovida como um serviço público, o que implica incorporar, na estrutura curricular, matérias de humanidades, previamente aprovadas pelo Ministério da Educação; 7) implementação da perspectiva de direitos humanos e de uma política transversal em matéria de gênero, possibilidade de acesso e progresso em condições de igualdade, erradicação de formas de violência, restrição da posse de armas exceto para as funções que as exijam, revogação do Código de Justiça Militar; 8) ativação do sistema de inteligência estratégica militar, sob a condução de uma autoridade civil; 9) fortalecimento dos laços com a sociedade civil, participação cidadã nos assuntos de defesa (Café Cultura Nación, encontros em unidades militares para fomentar o diálogo, ciclo de palestras Las mujeres y sus luchas en la Historia Argentina, mesas de discussão sobre a Guerra das Malvinas) e maior difusão por meio da imprensa oficial das ações desenvolvidas; 10) otimização dos mecanismos de transparência e controle público (Argentina 2009).

Dessa forma, de acordo com Ugarte (2012), toda análise que se efetue da política de defesa argentina deve, necessariamente, levar em consideração a alteração de rumo operada a partir de dezembro de 2005, promovida a partir do fortalecimento institucional e da reorganização do Ministério da Defesa. Todavia, foi durante o governo da presidenta Cristina Kirchner (2007-2015) que as questões de gênero se tornaram centrais na agenda de defesa. A presidenta, em conjunto com a ministra, foram as responsáveis pela idealização de importantes projetos. Alavancou-se, por meio da condução política do Ministério, uma 
mudança de paradigma das Forças Armadas calcada no ideal nacional La Patria es el otro, o qual sustenta que o outro constitui um insumo imprescindível para a construção do todo e, por essa razão, deve ser interpretado como um elemento inclusivo e igualitário, ou seja, um aspecto de completude e não de exclusão (Argentina 2014)

Essa concepção propiciou a transversalização da agenda de gênero e impulsionou a execução de leis e a ampliação de direitos. No âmbito da defesa, o ideário se insere no "desenvolvimento de condições de acesso igualitário e de equidade para que os homens e mulheres de armas possam desde seu lugar contribuir para construção de uma nova Nação, uma Pátria muito mais inclusiva, igualitária, livre e democrática" (Argentina 2014, p.14, tradução livre). Busca-se, portanto, que as Forças Armadas sejam um ambiente para a realização profissional e pessoal de mulheres e homens, no qual haja ampla possibilidade de acesso às funções e crescimento na carreira.

Medidas de caráter legal foram responsáveis, por exemplo, por expandir às mulheres militares direitos gozados por outros empregados da administração pública nacional. Anulou-se, assim, as disposições que discriminavam mulheres em sua condição materna e foram promovidas ações de combate à violência de gênero (Frederic 2013). Em síntese: a Resolução Ministerial $\mathrm{n}^{\circ}$ 849/06 eliminou as proibições de ingresso e permanência no Colégio Militar e na Escola de Aviação de alunas grávidas, em amamentação e com filhos. Excluiu-se as mulheres grávidas ou lactantes da tarefa de sentinela (Res. MD n ${ }^{\circ}$ 113/07), assim como das atividades de combate, tiro e qualquer outra que pudesse colocar em risco sua condição; eliminou-se a proibição de casamento entre militares de diferentes escalões, de distintas forças e de militares com membros das forças de segurança (Res. MD n 1352/07 e 601/08), adequando à normativa do casamento igualitário civil; eliminaram-se as distinções entre filhos adotivos ou biológicos, frutos do matrimônio ou não. Reformou-se o sistema judicial militar incluindo o assédio sexual, criaram-se projetos de saúde sexual e reprodutiva (Res. MD $n^{\circ} 28 / 10$ ) e elaborou-se um guia a fim de detectar, atender e registrar os casos de violência familiar (Escoffier \& Muleiro 2015; Argentina 2010).

Foi instituído, pela Resolução n 199/2008, o Plan Nacional de Jardines Maternales y Paternidad Responsable, com o objetivo de possibilitar a conciliação da jornada de trabalho e da vida familiar e, com isso, dar condições iguais para o desenvolvimento profissional de mulheres e homens das forças. As creches, destinadas aos filhos e filhas do pessoal civil e militar, foram operacionalizadas a partir da concessão de recursos ministeriais em parceria com governos locais, responsáveis pelo quadro docente (Argentina 2014).

A resolução $n^{\circ} 781$, de 2008 , determinou a composição de uma comissão para sugestão de alterações nos uniformes, levando em conta a execução das atividades por mulheres. Readequações nas estruturas físicas também foram propostas, como a adequação de espaços para a amamentação, projeto em consonância com a Lei Nacional $n^{\circ} 26.873$ de Promoción de la Lactancia Materna e com a Lei ${ }^{\circ} 2958$, da cidade de Buenos Aires, de Implementación de Lactarios em Instituciones del Sector Público, incorporando uma perspectiva de gênero no ambiente de trabalho (Bonifazzi 2015).

Salienta-se a Resolução $n^{\circ} 1143$, vigente a partir de 2011, que eliminou todas as restrições de acesso do contingente feminino aos distintos cargos e patamares militares, nelas incluídas as armas de combate - acontecimento singular que derrubou a última barreira legal que impedia as mulheres de se desenvolverem profissionalmente no âmbito castrense. Mediante essa Resolução, futuramente, as mulheres estarão aptas para alcançar postos de comando e intervir nos processos de tomada de decisão em condições de igualdade. 
${ }^{5}$ O Conselho Nacional das Mulheres é um outro espaço para debates, integrado pelo Ministério da Defesa argentino (Escoffier 2015).
${ }^{6}$ Como por exemplo: "Toda persona tiene derecho a una vida libre de violencia si conoces algún caso podes contactarse al xxxx"; "No seas víctima ni cómplice de violencia de género en el ámbito laboral Podés comunicarlo al $\mathrm{xxxx}$ " (Argentina 2014, pp.33-34).
No que tange às formas encontradas para institucionalizar e operacionalizar a discussão de gênero, no ano de 2007, foi publicado o primeiro de uma série de livros intitulados Equidad de Género y Defensa: una política en marcha. Trata-se de uma síntese anual das atividades realizadas pelo Ministério da Defesa na temática de gênero. Igualmente, datas simbólicas para as mulheres foram incorporadas ao calendário castrense, como o ato pelo Dia Internacional da Mulher Trabalhadora e o Dia Internacional de Não Violência Contra as Mulheres. Acentua-se, ainda no ano de 2007, a criação do Observatorio sobre la Integración de la Mujer en las Fuerzas Armadas e o Consejo de Políticas de Género para la Defensa, doravante denominado Conselho.

O Conselho foi composto por representantes das três forças, funcionários do Ministério da Defesa e acadêmicos. De acordo com Masson (2010), esse é um grande exemplo de uma política pública na qual se articulam diferentes setores institucionais e da sociedade civil, os quais aportam saberes técnicos, acadêmicos e empíricos em um diálogo pautado na confiança e no respeito. Experiências de mulheres militares e opiniões distintas dos membros convergem na construção de uma agenda de políticas que buscam aprimorar a condição feminina nas forças. Logo, o Conselho age como um órgão aglutinador de demandas $^{5}$ (Escoffier 2015).

Dentre suas atividades, o Conselho propôs, por exemplo, o estabelecimento de Oficinas de Gênero em cada força, constituídas como espaços para a canalização de denúncias e consultas vinculadas à temática de gênero - abuso de autoridade, situação de trabalho, discriminação, gênero, violência intrafamiliar e assédio sexual. Estão em funcionamento 21 oficinas nas três forças militares e no comando operacional do Estado-Maior Conjunto.

Mediante a recepção das denúncias, o propósito da Oficina é fornecer apoio e tratamento às mulheres e, se necessário, intervir em favor das vítimas, aliado a um compromisso de evidenciar o problema e evitar o aumento de casos. Para tanto, foram empregados os conceitos provenientes dos direitos humanos e trabalhistas, assim como rediscutidas as questões abordadas pelo feminismo, como a valorização patriarcal, por meio da qual os perpetradores dos atos de violência se veem, muitas vezes, em situações de privilégio (Argentina 2014; 2015).

Como parte da política de combate à violência de gênero, o Conselho incorporou no material de circulação oficial frases que abordam a violência e a discriminação com base no gênero ${ }^{6}$, estimulando a denúncia. Propôs que todos aqueles funcionários que desenvolvam tarefas relacionadas com a temática de gênero realizem um curso de aprimoramento em Gênero e Gestão Institucional para que, à disposição de ferramentas conceituais e metodológicas, possam melhor conduzir os casos.

Durante a década analisada, foram realizados seminários, congressos e reuniões para a promoção das novas leis, tanto em contexto nacional quanto regional. Nesse sentido, a sociedade argentina articula anualmente os Encuentros Nacionais de las Mujeres, evento de grande repercussão política e cultural, declarado de interesse para o âmbito da defesa. A Resolução n ${ }^{\circ}$ 89/2014 instituiu que as Forças Armadas garantam a participação de dez mulheres militares, formando uma comissão permanente para frequentar o encontro, no qual foi criada a Comisión de Mujeres, Fuerzas Armadas y de Seguridad, que trata temas como aborto, educação sexual, anticoncepção, acesso à educação, desenvolvimento laboral e acesso aos altos cargos (Argentina 2014).

Por outro lado, medidas foram adotadas também no intuito de transcender os limites nacionais. Para isso, foram elaborados indicadores de gênero para as pesquisas entre militares. Em tais avaliações periódicas, a distinção de sexo foi 
${ }^{7}$ Discurso proferido durante o Seminario Sudamericano: Las mujeres en el ámbito de la Defensa de la UNASUR, em 2013.

\section{O cenário brasileiro}

critério incluído, a fim de mensurar resultados e adequar as práticas empregadas. Por meio desse monitoramento, a Dirección de Políticas de Género colaborou com o Centro de Estudos Estratégicos para a Defesa da Unasul na elaboração de uma Matriz de Gênero do Setor da defesa latino-americana, uniformizando conceitos e criando ferramentas metodológicas de análise e informação (Argentina 2014).

Atualmente, a Argentina é uma referência regional na consolidação de políticas de gênero, as quais não ficaram restritas apenas em um governo ou administração. O ministro da defesa Augustín Rossi (2013-2015) deu continuidade às medidas, ciente da importância da participação feminina nas Forças Armadas ${ }^{7}$. Destarte, "os desafios que ainda restam estão presentes na sociedade como um todo, como por exemplo, a conciliação da vida familiar e a jornada de trabalho, a dupla ou tripla carga de trabalho, a responsabilidade sobre os filhos [...] Há uma necessidade preeminente por empoderá-las" (Escoffier 2015, entrevista às autoras).

O processo de feminização das Forças Armadas brasileiras teve início por meio da Marinha, em 1980, com a criação do Corpo Auxiliar Feminino da Reserva da Marinha. Porém, a real integração ocorreu apenas a partir do final da década de 1990, quando foram incorporadas as primeiras mulheres militares na estrutura oficial dos Corpos e Quadros da Marinha, com o ingresso da primeira turma feminina na Academia da Força Aérea, em 1996, e no Instituto Militar de Engenharia do Exército, em 1997.

No decorrer dos anos, observou-se uma evolução numérica dos efetivos de mulheres. Houve um crescimento de 2,9\%, em 2001, para 5\% em 2010, atingindo, em 2014, 6,6\% de mulheres nas Forças Armadas, de acordo com a Secretaria de Coordenação e Organização Institucional do Ministério da Defesa. Os dados coletados pela Pesquisa Nacional por Amostragem de Domicílio (PNAD), realizada pelo Instituto Brasileiro de Geografia e Estatística (IBGE), ao longo dos anos 2005 a 2013, também sinalizam um aumento, como se vê na Tabela 1.

De antemão, um importante fator para o número ainda baixo é a isenção do serviço militar obrigatório, do mesmo modo que a não admissão delas em determinados serviços militares voluntários, como na graduação de Cabo do Exército Brasileiro, não garante as mesmas condições de entrada asseguradas aos homens, o que dificulta a alteração da composição dos quadros. Além disso, condições femininas, como a gravidez, permanecem sendo um critério de

Tabela 1 - Membros da Forças Armadas e auxiliares

\begin{tabular}{lcc}
\hline Ano & Homens & Mulheres \\
\hline 2005 & $95 \%$ & $5 \%$ \\
2006 & $94,9 \%$ & $5,1 \%$ \\
2007 & $95,15 \%$ & $4,85 \%$ \\
2008 & $94,3 \%$ & $5,7 \%$ \\
2009 & $93,6 \%$ & $6,4 \%$ \\
2011 & $93,7 \%$ & $6,3 \%$ \\
2012 & $93,5 \%$ & $6,5 \%$ \\
2013 & $92,5 \%$ & $7,5 \%$ \\
\hline
\end{tabular}

Fonte: As autoras, a partir do PNAD-IBGE 2005-2013. 
exclusão. De acordo com a Portaria DEPENS (Departamento de Ensino da Aeronáutica) $n^{\circ} 102 / \mathrm{DE} 2$, de $1^{\circ}$ de agosto de 2002:

"Durante o período compreendido entre a inscrição no concurso de admissão e a conclusão do Curso de Formação de Oficiais Aviadores (CFOAV), a candidata ou cadete não deverá apresentar estado de gravidez, dada a incompatibilidade com os testes físicos específicos, de caráter seletivo, [...] e com as atividades físicas obrigatórias a que será submetida durante o curso. A comprovação do estado de gravidez acarretará a exclusão do concurso de admissão, ou o desligamento do CFOAV" (Portaria DEPENS 2002, p.8).

Na Marinha eliminou-se a restrição à participação de mulheres grávidas na seleção dos postos (Diário Oficial da União, 19/05/2015), contudo, continua a ser exigido o teste de gravidez de todas as mulheres na etapa inicial. A problemática se amplia dada a inexistência de creches e escolas capazes de atender aos filhos(as) das militares, atrelada às dificuldades que enfrentam durante a gestação e após o parto, frente à incompreensão de alguns comandantes sobre as limitações inerentes a esse período de vida. Tais situações fazem com que planos familiares sejam alterados em favor da carreira.

"O que estamos constatando é uma quebra de tabus em segmentos que não empregavam mulheres. Nas forças armadas, por exemplo, elas estão ingressando pelo oficialato. Para consolidar a posição no mercado, a mulher tem cada vez mais adiado projetos pessoais, como a maternidade. A redução no número de filhos é um dos fatores que têm contribuído para facilitar a presença da mão-deobra feminina, embora isto não seja visto pelos técnicos do IBGE como uma das causas da maior participação da mulher no mercado" (Probst 2015, p.6 apud Rovina \& Souza 2015).

Por outro lado, uma maior articulação das mulheres militares em grupos de discussão permitiu a conquista de direitos e a equiparação com os direitos de mulheres civis, como é o caso da proteção legal à maternidade assegurada pela Consolidação das Leis do Trabalho (CLT). Nesse sentido, foi implantada a licença à gestante e adotante por meio da Lei n ${ }^{\circ} 13.109$, de 25 de março de 2015, na qual as mulheres militares gestantes e militares (homens e mulheres) adotantes foram contempladas com os mesmos direitos concedidos às mulheres civis (Sancionada lei que garante licença-maternidade de seis meses às militares 2015). Igualmente, foram adicionados à Lei casos específicos da profissão militar, como a permissão para as futuras mães mudarem de função quando suas condições de saúde exigirem; foi garantido um intervalo de uma hora às militares em amamentação, divisível em dois períodos de 30 minutos para descanso até que o bebê complete seis meses; em casos de nascimento prematuro, a licença se inicia a partir do nascimento da criança, e são concedidos 30 dias de licença para as mulheres que sofrerem aborto (Direito à licençamaternidade de seis meses vai ser estendido às mulheres militares 2015.).

No Exército, foram conquistados recentes avanços no que tange à incorporação das mulheres nas frentes de batalha. A Academia Militar das Agulhas Negras (AMAN), a partir de 2017, por força do art. $7^{\circ}$ da Lei n ${ }^{\circ} 12.705$, de 2012, passou a incluir mulheres na linha de ensino bélico, limitadas, entretanto, aos cursos de Material Bélico e de Intendência. Por essa via garante-se que as mulheres estarão aptas a atingir o posto máximo da carreira, General de Exército.

Na Marinha, a mulher mais antiga é a Contra-Almirante Médica Dalva Maria Carvalho Mendes promovida em 2012 ao posto máximo da carreira para oficiais médicos, um marco relevante na história da organização. Em 2014, a Marinha iniciou o processo de admissão de aspirantes femininas na Escola Naval (Concurso Público de Admissão à Escola Naval - CPAEN). Não obstante, permanece vigendo a Lei ${ }^{\circ}$ 9.519/1997, que impede a entrada de mulheres para 
${ }^{8}$ O PNPM 2013/2015 atribui ao MD a linha de ação 4.3 a qual dispõe sobre o fortalecimento da segurança cidadã e acesso à justiça às mulheres em situação de violência. Torna de responsabilidade do MD diagnosticar as competências necessárias para atuação das mulheres nas Tropas de Paz; capacitar as Tropas na perspectiva de gênero e estabelecer parcerias para prevenção das DSTs/HIV. os Corpos da Armada e de Fuzileiros Navais (setores combatentes da Marinha), ao prever que esses deverão ser ocupados por oficiais do sexo masculino.

Na Força Aérea Brasileira, ressalta-se a presença de mulheres pilotos de caça pertencentes à elite combatente, as quais foram submetidas a rigorosos testes físicos, intelectuais e psicológicos para alcançarem tal posto, que permite acessarem o cargo de Comandante da Aeronáutica (Miyaguti 2015 apud Rovina \& Souza 2015). A Força Aérea planeja, ainda, o ingresso de jovens mulheres na Escola Preparatória de Cadetes do Ar. Caso alcance a meta serão novamente um exemplo para as demais forças.

Nesse ínterim analisado, salienta-se a importante criação, em abril de 2014, da Comissão de Gênero do Ministério da Defesa (CGMD), composta por representantes dos comandos das Forças Armadas e de diversos setores do Ministério, com caráter consultivo. Em seu plano de ação formulado em 2015, a Comissão se propõe a: orientar a atuação do Ministério da Defesa (MD) visando à efetivação dos direitos das mulheres e da igualdade de gênero; acompanhar e avaliar o cumprimento das ações definidas no Plano Nacional de Políticas para as Mulheres (PNPM), sob a responsabilidade do $\mathrm{MD}^{8}$; articular os órgãos desse Ministério na implementação das ações propostas; contribuir para a atuação do MD nos espaços institucionais que tratam das políticas para as mulheres e de gênero; sensibilizar e capacitar servidores e dirigentes do Ministério, com o objetivo final de aprofundar e transversalizar a temática de gênero no âmbito da defesa brasileira (Lima 2015).

Para tanto, a Comissão se propôs a desenvolver um projeto de pesquisa para diagnosticar as questões de gênero relevantes no âmbito da defesa; conduzir a implementação das ações da PNPM sob a responsabilidade do MD, articulando os órgãos envolvidos; propor parâmetros para a implementação da Resolução 1.325 do Conselho de Segurança da ONU; contribuir para a participação qualificada do MD em conferências e seminários, nacionais e internacionais sobre a temática de gênero; criar um espaço no sítio do MD para a Comissão de Gênero do Ministério da Defesa (CGMD).

Contudo, apesar da importância da criação da Comissão e o avanço institucional conquistado, os resultados das ações são frágeis, haja vista o projeto supracitado que, após solicitação de dilatação dos prazos, permanece inconcluso (CGMD 2015a, CGMD 2015b). Há constantes discordâncias entre os membros, os quais expressam opiniões e interesses de grupos particulares, a exemplo da proposta de realização de uma pesquisa sobre a situação atual do trabalho feminino. De um lado, posicionaram-se aqueles que compreendiam que a consecução de tal pesquisa era fundamental para o andamento das atividades, porém, de outro, estavam aqueles que acreditavam que uma pesquisa incorreria em um viés civil e teria alcance muito limitado, dada a incompreensão de questões operacionais, culturais, valores e missões das forças. Para mais, ela fragilizaria a coesão institucional, pois os homens poderiam se sentir desprivilegiados (CGMD 2015c).

Entre os tópicos polêmicos figura o assédio sexual. Para alguns, a questão deveria ser barrada, uma vez que o ato é tipificado como um crime e, por essa razão, já é combatido pela corporação. Entretanto, para outros, a percepção feminina não deveria incorrer em uma censura prévia, uma vez que o órgão foi criado justamente para averiguar a situação da mulher na Defesa (CGMD 2015c). Militares afirmaram que a situação feminina deve ser estudada de forma integral, sem se ater em assuntos que fujam ao escopo da Política Nacional (CGMD 2015c).

A disponibilização das informações também motiva discussões. O tema das mulheres na defesa atrai atenção e questionamentos de muitas pessoas que 
frequentam a página na internet do $\mathrm{MD}$. Na opinião do representante do Exército, o seu centro de comunicações estaria apto a responder todas as perguntas, no entanto, por se tratar de uma página do Ministério a responsabilidade seria do ministro (CGMD 2015c).

A despeito dos entraves a Comissão contribui para a participação de seus membros, civis e militares em seminários, palestras e cursos, com vista a uma melhor capacitação sobre a temática e estabelecimento de um diálogo regional sobre o assunto, como os debates acerca da homologação de conceitos de gênero no Conselho de Defesa Sul-Americano, realizados em setembro de 2015, no Chile (CGMD 2015d).

Destarte, a baixa profissionalização dos militares e o temor da mudança implicam constrangimentos na implantação de políticas com a perspectiva de gênero. Da mesma forma, assentados no machismo, característico da instituição militar, a ordem interna prevalece em detrimento de um debate transparente. Portanto, à semelhança da sociedade "também na caserna são mudanças culturais profundas que levarão a uma verdadeira igualdade de gênero" (Mathias \& Adão 2008, p.298).

\section{Conclusões}

${ }_{9} \mathrm{O}$ ato de empossar um civil como ministro não garante $o$ controle das Forças, tampouco a figura do Ministério afiança a não-intervenção militar na vida política (Winand \&AMP; Saint-PIERRE 2007).
Em face do estudo de cada caso, depreende-se que na Argentina a suspensão do serviço militar obrigatório por meio da Lei 24.429, em 1994, foi crucial para a profissionalização militar. Reconheceu-se, naquele momento, muito além da capacidade física das mulheres, mas a contribuição que elas aportariam a um espaço até então masculino (Badaró 2015; Frederic 2013). Todavia, no que tange à década sob observação, o fator preponderante para o desenvolvimento de políticas de gênero diz respeito à capacidade conferida ao Ministério da Defesa de formular as políticas de defesa e controlar sua execução. Resultado de uma condução emblemática por parte da gestão da ministra Nilda Garré, a qual contribuiu para a reformulação da condução ministerial das Forças Armadas (Diamint 2008).

Entre as pautas propostas, a incorporação da perspectiva de gênero na defesa conquistou novo olhar, sob a égide dos direitos humanos. Em virtude desse empenho pessoal, acrescido de um Ministério da Defesa fortalecido e impositivo, a Argentina consagrou-se por conceber um sistema novo, tornando-se um exemplo na implantação de políticas de equidade. Atualmente, logrou alcançar a incorporação das mulheres em todos os papéis militares, ou seja, não existem funções restritas a elas e seus planos de carreira são os mesmos dos homens. As políticas não cessaram sob o comando do seguinte ministro da defesa, mas é interessante observar que a administração mais incisiva e reformista, desde a redemocratização, foi conduzida por uma mulher.

Por outro lado, no caso brasileiro, a questão de gênero foi integrada às discussões da defesa apenas muito recentemente e, tendo em vista a letargia com que evoluem, apesar das tentativas propostas pelo Ministério da Defesa, nota-se que: (1) apesar de sucessivas gestões democráticas, ainda não houve o estabelecimento de um controle civil adequado sobre os militares, tendo a sociedade pouca atuação na formulação e implementação das políticas de defesa, demonstrando a ainda imatura relação civil-militar e a fragilidade do Ministério da Defesa'; (2) a instituição militar tem pouco interesse na formulação de políticas que visem aprimorar a condição feminina no interior da organização. Esta prática sexista limita a carreira feminina e demonstra que há um longo caminho a ser percorrido pelas mulheres nas Forças Armadas brasileiras.

Portanto, a não implementação de processos de reforma e modernização do setor de defesa pelos dirigentes civis inviabiliza a equidade de gênero. Ao passo 
que a confecção de uma agenda de gênero está atrelada à profissionalização das forças armadas, a qual corresponde ao exclusivo cumprimento do propósito institucional de defesa da sociedade e abandono da posição de preponderância no cenário político nacional. O estabelecimento da defesa como uma política de Estado permite que demandas sociais advindas de um contexto de mudanças sejam implementadas.

Entretanto, apesar das divergências apontadas, em ambos cenários a incorporação efetiva das mulheres não foi concluída. As mulheres permanecem enfrentando dilemas sociais, como as responsabilidades familiares e a hierarquização social que as mantêm distantes do topo da estrutura. Portanto, o principal desafio não está associado ao aumento do número de mulheres militares, mas sim à proposição de políticas que estejam atentas às demandas femininas e que coloquem fim aos atos de violência, condutas sexistas e discriminações veladas.

Natália Diniz Schwether (natidiniz@ gmail.com) é Doutoranda em Ciência Política pela Universidade Federal de Pernambuco (UFPE). Vínculo institucional: Programa de Pós-Graduação em Ciência Política, Universidade Federal De Pernambuco, Recife, PE, Brasil.

Graciela de Conti Pagliari (graciela.pagliari@gmail.com) é Doutora em Relações Internacionais pela Universidade de Brasília (UNB) e Professora do Departamento de Economia e Relações Internacionais da Universidade Federal de Santa Catarina (UFSC). Vínculo institucional: Departamento de Economia e Relações Internacionais, Universidade Federal de Santa Catarina, Florianópolis, SC, Brasil.

\section{Referências}

Almeida, V., 2015. Mulheres nas Forças Armadas brasileiras: situação atual e perspectivas futuras. Cadernos ASLEGIS, 51, pp.93-134.

Badaró, M., 2015. Dentro y fuera del cuartel: transformaciones en la vida cotidiana del ejército argentino (1990-2010). Voces en el Fénix, 48.

Barrancos, D., 2015. Relaciones de género en el ámbito de defensa: el camino hacia la equidad. Voces en el Fénix, 48.

Baquim, C., 2007. Mulher e piloto: o caso das pioneiras da aviação militar brasileira. In $1^{\circ}$ Encontro da Associação Brasileira de Estudos de Defesa. São Carlos

Battistelli, F., 1999. As mulheres e o militar entre antigas dificuldades e novas potencialidades. Nação e Defesa, 88, pp45-70.

Bobea, L., 2008. Mujeres en uniforme: la feminización de las Fuerzas Armadas. Nueva Sociedad, 213, pp.64-79.

Bonifazzi, F., 2015. Mujeres pioneras en las Fuerzas Armadas: la gestión pública narrada desde sus protagonistas. In C. Mazzota, ed. Equidad de Género y Defensa: una política en marcha IX. Buenos Aires: Ministerio de Defensa.

Carreiras, H., 2010. Gendered Culture in Peacekeeping Operations. International Peacekeeping, 17(4), pp.471-485. DOI: $10.1080 / 13533312.2010 .516655$ 2013. Mulheres, direitos e eficácia militar: o estado do debate. Revista Militar, 2536, pp.477-495.

Chambouleyron, I. \& Resende, E., 2006. Duque de Caxias e Maria Quitéria na mesma trincheira: o questionamento das representações do masculino e feminino pela mulher combatente. In XXX Encontro Anual da ANPOCS. Caxambu.

D’Araújo, M., 2003. Mulheres e questões de gênero nas Forças Armadas brasileiras. Resdal. Disponível em: http://www.resdal.org/producciones-miembros/redes-03-daraujo.pdf. Acesso em: 29 jan. 2018.

Diamint, R., 2008. La historia sin fin: el control civil de los militares en Argentina. Nueva Sociedad, 213, pp.95-111.

Escoffier, N. \& Muleiro A., 2015. Resolución 93/2014: producción de indicadores y su vinculación con la transversalización de la perspectiva de género. In C. Mazzota, ed. Equidad de Género y Defensa: una política en marcha IX. Buenos Aires: Ministerio de Defensa.

Farah, M., 2004. Gênero e políticas públicas. Revista Estudos Feministas, 12(1), pp.47-71. DOI: /10.1590/s0104026x2004000100004

Frederic, S., 2013. Las Trampas del Pasado: las Fuerzas Armadas y su integración al Estado democrático en Argentina. Buenos Aires: Fondo de Cultura Económica.

Friedman, E., 2003. Gendering the Agenda: The Impact of the Transnational Women's Rights Movement at the UN Conferences of the 1990s. Women's Studies International Forum, 26(4), pp.313-331. DOI: 10.1016/s0277-5395(03)00077-3

Granizo, E., 2008. La Incorporación de la Mujer en las Fuerzas Armadas. In: Barrancos, Dora (et.al.). Las Mujeres y sus luchas en la Historia Argentina. Ministerio de Defensa: Buenos Aires. pp.173-180

Herbert, M., 1998. Camouflage Isn't Only for Combat: Gender, Sexuality, and Women in the Military. New York University Press: New York-London.

Héritier, F., 1996. Masculino e Feminino o pensamento da diferença. Instituto Piaget: Lisboa. 
Martínez, V., 2009. Las Mujeres em los ejércitos europeos y americanos. In: Escarda, María Gómez; Muñoz Isidro S. Las mujeres militares en España (1988-2008). Instituto Universitario General Gutiérrez Mellado: Madrid.

Masson, L., 2010. Las mujeres en las Fuerzas Armadas. ¿Qué tipo de integración? In N. Garré, ed. Género y Fuerzas Armadas: algunos análisis teóricos y prácticos. Buenos Aires: Ministerio de Defensa/Fundación Friedrich Ebert.

Mathias, S., 2005. As mulheres chegam aos quartéis. In XXIII Simposio Nacional de Historia. Londrina.

Mathias, S. \& Adão, M., 2013. Mulheres e vida militar. Cadernos ADENAUER, 14(3), pp.145-165.

Miyaguti, A., 2015. Comando da Aeronáutica. Palestra apresentada na $2^{a}$ Reunião Ordinária da Comissão de Gênero do MD, Brasília.

Oliveira, E. R., 2006. Considerações políticas sobre a defesa nacional. Revista eletrônica de jornalismo científico, São Paulo, Sociedade Brasileira para o Progresso da Ciência (SBPC).

Perrot, M., 1998. Mulheres públicas. São Paulo: Editora da UNESP.

Probst, E., 2015. A evolução da mulher no mercado de trabalho. Instituto Catarinense de Pós-Graduação (ICPG). Gestão Estratégica de Recursos Humanos.

Rocha, A. J. R., 2011. Militares e Política no Brasil, IPEA: Brasília.

Rovina, D. \& Souza, N., 2015. A mulher militar brasileira: conquistando mares, alçando voos e desbravando terras. Laboratório ESG.

Saint-Pierre, H., 2014. Introdução à análise e formulação de política de defesa. Digit.

Santos, L., 2014. Da Roseta às Estrelas: um debate sobre a representação feminina na Marinha brasileira. Dissertação de Mestrado. Universidade Estadual Paulista.

Schwether, N., 2015. Depoimento de Natália Escoffier. In __. Agora é que são elas: desvendando o processo de incorporação das mulheres nas Forças Armadas de Brasil e Argentina. Dissertação de Mestrado. Universidade Federal de Santa Catarina.

Scott, J., 1989. Gender: a useful category of historical analyses. Gender and the politics of history. Columbia University Press: New York.

Soares, V., 2013. Percepções e Atitudes: ser mulher e participação política. In: G. Venturi \& T. Godinho, eds. Mulheres Brasileiras e Gênero nos Espaços Público e Privado: uma década de mudanças na opinião pública. São Paulo: Fundação Perseu Abramo/Edições Sesc SP.

Soares, V., 1994. Movimento de mulheres e feminismo: evolução e novas tendências. Revista Estudos Feministas, n. especial, pp.11-24.

Stromquist, N., 1996. Políticas públicas de Estado e eqüidade de gênero. Revista Brasileira de Educação, 1, pp.27- 49.

Vaz, D., 2013. O teto de vidro nas organizações públicas: evidências para o Brasil. Economia e Sociedade, 22(3), pp.765-790.

Stell, Andrea V., 1997. Organizações, gênero e posição hierárquica - compreendendo o fenômeno do teto de vido. Revista de Administração, São Paulo, 32, pp.62-69

Ugarte, J., 2013, Argentina en el escenario latino-americano actual: debates desde las ciencias sociales. VII Jornadas de Sociologia de la Universidad de la Plata, La Plata.

Winand, É. \& Saint-Pierre, H., 2007. O Legado da transição na agenda democrática para a defesa: os casos brasileiro e argentino. In H. Saint-Pierre et al., eds. Controle civil sobre os militares: e a política de defesa na Argentina, no Brasil, no Chile e no Uruguai. Programa San Tiago Dantas de Pós-Graduação em Relações Internacionais.

Youngs, G., 1999. International Relations in a Global Age: a Conceptual Challenge. Cambridge: Polity Press.

\section{Outras fontes}

Direito à licença-maternidade de seis meses vai ser estendido às mulheres militares. 2015. Notícias do Ministério da Defesa. 6 mar. Disponível em: http://www.defesa.gov.br/noticias/15172-direito-a-licenca-

maternidade-e-estendida-as-mulheres-militares. Acesso em 29 jan. 2018.

Argentina 2009. Modelo Argentino de Modernización del Sistema de Defensa. Buenos Aires: Ministerio de Defensa.

Argentina 2010. Informe sobre la integración de la mujer en las Fuerzas Armadas. Buenos Aires: Ministerio de Defensa.

Argentina 2013. Equidad de Género y Defensa: Una Política en Marcha VII. Buenos Aires: Ministerio de Defensa.

Argentina 2014. Equidad de Género y Defensa: Una Política en Marcha VIII. Buenos Aires: Ministerio de Defensa.

Argentina 2015. Equidad de Género y Defensa: Una Política en Marcha IX. Buenos Aires: Ministerio de Defensa.

CGMD, 2014a. I Seminário de Capacitação da Comissão de Gênero MD 04 de set de 2014. Memória de Reunião nº 12014 CGMD, p.1-16

CGMD, 2014b. 1 ${ }^{a}$ Reunião Ordinária da Comissão de Gênero MD 06 de nov de 2014. Memória de Reunião n²2 2014 CGMD, pp.1-4

CGMD, 2015a. $2^{a}$ Reunião Ordinária da Comissão de Gênero MD 09 de fev de 2015. Memória de Reunião n³ 2015 CGMD, pp.1-10

CGMD, 2015b. $3^{a}$ Reunião Ordinária da Comissão de Gênero MD 28 de abr de 2015. Memória de Reunião n4 2015 CGMD, pp. 1-11

CGMD, 2015c. $4^{a}$ Reunião Ordinária da Comissão de Gênero MD 03 de jul de 2015. Memória de Reunião n5 2015 CGMD, pp.1-16

CGMD, 2015d. 2015. Relatório nº01. Seminário sobre Incorporação da Perspectiva de Gênero na Educação Militar, ANEPE, Chile. 
Portaria DEPENS, 2002. Instruções Específicas para o Exame de Admissão ao Curso de Formação de Oficiais Intendentes. Brasília: Comando da Aeronáutica, Ministério da Defesa.

Sancionada lei que garante licença-maternidade de seis meses às militares, 2015. DEFESANET. Brasília, 27 mar.

Disponível em: http://www.defesanet.com.br/defesa/noticia/18551/Sancionada-lei-que-garante-

licenca-maternidade-de-seis-meses-as-militares/. Acesso em: 29 jan. 2018.

\section{Gender Policies for Defense: the cases of Argentina and Brazil}

ABSTRACT Introduction: The article proposes to list gender policies for Defense adopted by the governments of Argentina and Brazil in the period of 2005 to 2015. The relevance of the Argentine case stems from the country that has shown very active practices of its Defense Ministry. On the other hand, in Brazil occurs the recent establishment of the Commission of Gender in the Ministry of Defense, which aims to achieve the women's rights and gender equality. Methods: Therefore, through a qualitative approach, procedural and historical the analysis uses primary sources from annual publications, reports and minutes of meetings in both countries. Results: From the analysis of the two cases, it can be seen that, even in the face of a scenario in which the effective incorporation of women has not yet been completed, the institution of a strong and taxing Ministry of Defense capable of controlling the proposed policies, linked to a which establishes equity as one of its presuppositions, were the requirements that allowed Argentina to become a regional exponent in the theme of gender. Discussion: Although the current debate on gender in the Armed Forces is relevant, the scientific contributions to the field are limited. Thus, the results presented are a way of updating the empirical data on the issue and provide inputs to expand the discussion about gender in the Armed Forces in Latin America.

Keywords: Military; Ministry of Defense; Gender; Brazil; Argentina.

This is an Open Access article distributed under the terms of the Creative Commons Attribution Non-Commercial License which permits unrestricted non-commercial use, distribution, and reproduction in any medium provided the original work is properly cited. 